\title{
A PRoeminência dA teorizaçÃo dE GÊnero PARA A PESQUISA EM HISTÓRIA
}

\section{ARTIGO DE REVISÃO}

RIBEIRO, Vagno Batista ${ }^{1}$

CATARINO, Elisangela Maura ${ }^{2}$

PURIFICAÇÃO, Marcelo Máximo ${ }^{3}$

RIBEIRO, Vagno Batista. CATARINO, Elisangela Maura. PURIFICAÇÃO, Marcelo Máximo. A proeminência da teorização de gênero para a pesquisa em história. Revista Científica Multidisciplinar Núcleo do Conhecimento. Ano 05, Ed. 01, Vol. 02, pp. 69-80. Janeiro de 2020. ISSN: 2448-0959, Link de acesso: https://www.nucleodoconhecimento.com.br/historia/proeminencia-dateorizacao

${ }^{1}$ Mestre em Teologia - Educação Comunitária Infância e Juventude pela Escola Superior de Teologia - EST. Doutorando em História pela Universidade do Vale do Rio dos Sinos - UNISINOS.

2 Doutora em Ciências da Religião pela Pontifícia Universidade Católica de Goiás PUC-Goiás. Em Estágio Pós-doutoral pela Escola Superior de Educação de Coimbra - ESEC. Professora Titular C-II no UNIFIMES/FIMES.

3 Pós-doutor em Educação pela Universidade de Coimbra. Doutor em Ciências da Religião pela Pontifícia Universidade Católica de Goiás - PUC-Goiás. Professor Titular C-II, no UNFIMES/GO, Professor Permanente no Programa de Pós-Graduação em Educação da Faculdade de Inhumas (PPGEdu/FACMAIS) e Professor Permanente no Mestrado Profissional em Intervenção Educativa e Social - MPIES da Universidade do Estado da Bahia - UNEB. 


\section{RESUMO}

Nas últimas décadas, a pesquisa em história vem sendo enriquecida com aportes da teorização de gênero. Novos atores e perspectivas passam a ser colocados em discussão, principalmente as relações de poder no seio do que se passou a denominar de patriarcado, isto é, a dominação masculina como processo linguístico de construção social no qual são reificadas relações binárias de percepção do sexo e da reprodução humana. Nesse sentido, o presente artigo busca analisar alguns elementos acerca da pesquisa em história no sentido de elencar algumas possibilidades que a teorização de gênero permite ao historiador e à historiadora quanto à difícil equação entre identidade e movimento social. $\mathrm{O}$ texto a seguir está organizado da seguinte maneira: uma breve avaliação acerca da relação entre heteronormatividade e a situação histórica das mulheres, seguida de uma consideração a respeito do gênero como categoria de análise histórico-linguística, concluindo por uma análise das dificuldades que os movimentos sociais encontram na elaboração de pautas que enfatizem a identidade ao mesmo tempo que permitem avançar na crítica radical de moralidades excludentes e desiguais.

Palavras-chave: Gênero, movimento social, identidade.

\section{INTRODUÇÃO}

Os pesquisadores e pesquisadoras da área de história que passaram a fazer uso da teorização de gênero se vinculam às teorias da linguagem, conferindo-lhe, porém, um outro olhar, perfazendo distinções entre o mundo da cultura e o da biologia; o natural e o social se correlacionam interpretativamente. Dessa forma, convencionou-se a relacionar palavras como sexo à biologia, isto é, o sexo seria parte da natureza sobre a qual não haveria nenhum tipo de participação dos grupos sociais na definição de seu significado, sendo evidente por si mesmo. Decorre dessa noção a respeito de coisas evidentes em si mesmas que as diferenças percebidas entre os sexos se estruturam por meio da linguagem que refere situações cotidianas e pautam relações de poder no interior de uma determinada sociedade. Para problematizar a maneira pela qual as relações binárias encontram ressonância na sociedade e produzem, 
consequentemente, a exclusão de minorias, a teorização de gênero passou a se referir aos processos de construção social das instituições e dos processos significantes. A teorização de gênero é uma forma de enfatizar o caráter social e, portanto, histórico, das concepções baseadas nas percepções das diferenças sexuais.

O objetivo fundamental deste artigo é abordar sob uma perspectiva de gênero a dinâmica entre heteronormatividade, como padronização simbólica do patriarcado, e os processos de luta por identidade, pautados pelos movimentos sociais, tratando essas noções como conceitos históricos. Para tanto, cumpre tratar especificamente dos seguintes pontos, a normalidade da epistemologia masculina tomada sob uma ótica da naturalidade biológica, a consequente relevância para a pesquisa em história da teorização de gênero como categoria de análise histórico-linguística e, por fim, a relação da luta por identidade e a necessidade da crítica radical às moralidades excludentes, isto é, binárias.

\section{HISTÓRIA E HETERONORMATIVIDADE}

A construção da normatividade se constitui num processo de disputa pela elaboração de conhecimentos travado mediante à invisibilidade do cotidiano ordinário, reificandose padrões e esquemas tomados desde os interesses que determinados grupos sociais concebem como apropriados à manutenção de seus privilégios (LUKÁCS,1974). É nesse aspecto que se faz necessário resgatar os conhecimentos e os saberes que foram negados ao corpo feminino, pois é justamente no negar o espaço formal de sociabilização, no qual as mulheres resistiram, e resistem, e dessa forma desenvolveram, e desenvolvem, constituindo saberes subterrâneos à lógica acadêmica e eurocêntrica aplicada aos mais distintos espaços formais da sociedade.

O conhecimento científico e acadêmico sempre foi relutante à presença das mulheres. Um saber que despreza a contribuição das mulheres não é apenas um conhecimento limitado e parcial, mas um conhecimento que mantém um caráter excludente. A caracterização acerca da construção dos saberes das mulheres se deriva da contramão do saber sistematizado, validado e inteligível, masculinamente racionalizado. Isso decorre da negação do lugar político e público do corpo feminino, 
sendo a ele permitido apenas o espaço privado e não o público, condicionando-o às normas de moralidade impostas pelo domínio do patriarcado (BOURDIEU, 2014). A negação dos direitos sociais e políticos das mulheres acarretam numa construção do saber cultural hegemônico que nega e priva as experiências e os valores femininos na construção coletiva e conscienciosa dos saberes, ainda que a parte importante do saber das mulheres seja incorporado sub-repticiamente, como é o caso do cuidado da saúde e da gestão econômica das famílias, entre outras esferas (ESTEVES, 1989). Ou seja, a metodologia, bem como o conteúdo dos processos formais de sociabilização e educação, ocasiona envolturas à cultura do patriarcado que busca manter e articular a lógica da sociedade da mercadoria, encobrindo a contribuição efetiva das mulheres, autorizada ou não.

Evidentemente, o poder de construir conteúdos e saberes ficou atrelado ao padrão étnico, classista e sexual dominante, a saber, à pessoa branca, privilegiada e do sexo e identidade masculina, criando o que se convencionou designar por heteronormatividade; os valores reificados do homem ocidental de tradição judaicocristã e islâmica. Dessa forma, com "pouca" história escrita pelas mulheres, ao longo do tempo, o conhecimento passou a ser totalmente controlado pelos homens. Para a análise de estudiosas feministas, conhecimento e educação são dois lados da mesma moeda, e desse modo, cabe um processo complexo de ruptura do padrão dominante estabelecido na busca por outros mecanismos de produção e sistematização dos conhecimentos, fundamentalmente aqueles relacionados à produção da história (GONÇALVES, 2006).

Distinguindo-se da categoria mulher ou mulheres, a noção de gênero encontrou na última década uma aplicação teórica mais abrangente a respeito das relações sociais mediadas pela linguagem (PEDRO, 2011). No sentido da análise de gênero, a produção historiográfica pelo viés da heteronormatividade produziria diferenças sexuais categoriais de poder social, dando aos homens o protagonismo do fazer história. Isso significa que a própria produção de poder estabelecida na sociedade entre os gêneros resultaria da reificação de relações assimétricas historicamente construídas. Portanto, teoriza Scott, "[...] gênero é um elemento constitutivo de 
relações sociais fundadas sobre as diferenças percebidas entre os sexos e o gênero é um primeiro modo de dar significado às relações de poder" (SCOTT, 1990). A noção de gênero como categoria de análise permite descontruir as teorias a respeito da naturalidade das relações sociais entre mulheres e homens, entre mulheres e mulheres e entre homens e homens, além de integrar em seu campo de análise as disforias de gênero.

O grande impacto que [o gênero] vem produzindo nas análises sociais funda-se em ter chamado a atenção para o fato de que uma parte da humanidade estava na invisibilidade - as mulheres -, e seu uso assinala que, tanto elas quanto os homens são produto do meio social, e, portanto, sua condição é variável. Além disso, 'gênero' dá ênfase ao caráter fundamentalmente social, cultural, das distinções baseadas no sexo, afastando o fantasma da naturalização [...]. (SPIZZIRRI, 2014, p. 42-44).

Nessa dimensão, para o desenvolvimento de uma historiografia que considere consequentemente a situação e o lugar das mulheres, é crucial que o protagonismo feminino esteja no centro e que seja ele constituído de novos referenciais na busca da desconstrução de outra forma de lidar com as relações sociais, agora estabelecida pelo diálogo e parceria entre homens e mulheres. Nessa dinâmica, um olhar epistemológico feminista possibilita referenciar no encontro ou na redescoberta da voz feminina, nos mais diversos espaços e períodos históricos, uma grande ampliação acerca da compreensão histórica como produto das relações humanas e suas dinâmicas corporais com seu meio ambiente. Assim, é fundamental alocar ao centro as mais diversas vozes e construções adormecidas, apostando na experiência dos cotidianos ordinários e desprestigiados ao longo da história, como são as vozes das mulheres que, embora tenham contribuído enormemente para o avanço das mais variadas formas de organizações e instituições sociais (igrejas, hospitais, governos, guerras, escolas, etc.), são silenciadas nos relatos normativos e nos prospectos institucionais elaborados pelo viés masculino heteronormativo. 


\section{GÊNERO COMO CATEGORIA DE ANÁLISE HISTÓRICO- LINGUÍSTICA}

A conceituação da desigualdade dada no contexto social para com as mulheres se evidencia na estrutura social brasileira cujos lugares de decisão de poder estão ocupados majoritariamente por homens brancos e, geralmente, emoldurados pelos valores heteronormativos. As lutas das mulheres, suas dificuldades vigentes, o silenciamento histórico no qual suas histórias e vivências são concebidas a partir do esquecimento da história como elaboração humana, produzindo a desmemorialização acerca dos mecanismos que engendram as relações de poder, baseadas nas diferenças percebidas entre os sexos, como modo de identificar o domínio masculino à natureza (BOURDIEU, 2014), tudo isso deveria implicar numa efetiva participação das mulheres no processo gerencial da vida social para além de sua função geradora.

Verifica-se que a participação histórica das mulheres não foi suficiente para quebrar os paradigmas do patriarcado, do machismo que impera na sociedade moderna e, por consequência, em grande parte das ciências.

$\mathrm{Na}$ organização social de gênero, homens e mulheres são alocados em lugares hierarquicamente diferenciados. A religião, indiscutivelmente, é uma das responsáveis pela produção e reprodução dessa hierarquia dos sexos, sacralizando papéis sociais culturalmente construídos. A religião, no campo da construção simbólica, tem cumprido a função social de constituição do feminino e do masculino, e é uma das grandes responsáveis pela inferiorização e secundarização das mulheres na sociedade brasileira (GEBARA, 2000).

Scott considera que o gênero pode ser percebido a partir de determinados elementos constitutivo das relações sociais baseadas nas diferenças percebidas entre os sexos, implicando em quatro elementos relacionados mutuamente, quais sejam:

- Designativos simbólicos culturais disponíveis que apresentam representações múltiplas e contraditórias; 
- Conceitos interpretativos que buscam normatizar a produção dos sentidos, limitando assim, as possibilidades metafóricas de ampliação dos símbolos culturais. Tais conceitos se expressam em concepções religiosas, educacionais, científicas, políticas e jurídicas, entre outras, tomando formas binárias de oposição, que acabam afirmando, categoricamente, os sentidos normativos do que seja o masculino e o feminino;

- Divisão representativa binária dos gêneros (divisão do mundo);

- Identidade marcada pela dimensão subjetiva (SCOTT, 1990, p. 86-88).

Scott afirma que a palavra gênero é ainda confundida com o estudo das mulheres, pois o conteúdo das pesquisas continua tratando de "mulheres", o que reforçaria a ideia comum de que gênero equivaleria ao "estudo sobre mulheres". Por isso é importante que historiadores e historiadoras busquem desfazer esse nó conceitual, especificando a teorização de gênero como esfera da sociabilidade humana mediatizada pela linguagem. "Através da linguagem é construída a identidade generificada (gendered)" (SCOTT, 1990, p. 82). Partindo dos estudos pósestruturalistas, pesquisadores e pesquisadoras começaram a dimensionar às relações sociais teorias da linguagem como a de Lacan, cuja percepção acerca do Inconsciente freudiano deslocou do corpo humano para o corpo das estruturas linguísticas e simbólicas das sociedades. Para Lacan, o Inconsciente seria uma estrutura de linguagem na qual habitariam os seres humanos e nas qual se estruturariam as relações de poder (ZIZEK, 1992). Lastreia a teorização de gênero a ideia freudiana a respeito da relação dos infantes a felicidade do genitor, isto é, da relação da criança com a lei de dependência da diferença sexual e de sua identificação imaginativa (ou fantasmática) com a masculinidade ou com a feminilidade.

Em outras palavras, a imposição de regras de interação social é inerente e especificamente generificada, pois a relação feminina com o falo é forçosamente diferente da relação masculina. Mas a identificação de gênero, mesmo que pareça sempre coerente e fixa, é, de fato, 
extremamente instável. Como sistemas de significado, as identidades subjetivas são processos de diferenciação e de distinção, que exigem a supressão de ambiguidades e de elementos de oposição, a fim de assegurar (criar a ilusão de) uma coerência e (de) uma compreensão comum. A ideia de masculinidade repousa na repressão necessária de aspectos femininos - do potencial do sujeito para a bissexualidade - e introduz o conflito na oposição entre o masculino e o feminino (SCOTT, 1990, p. 82).

Gênero se constitui, dessa forma, como uma categoria de análise dos processos históricos acerca das relações estabelecidas em meio à sociabilização humana mediatizada pela linguagem como ambiente no qual se estruturam significados, ou como afirma Scott (1990): "[...] o gênero é um campo primário no interior do qual, ou por meio do qual, o poder é articulado". E essa articulação do poder nas relações sociais não é a única, mas se caracteriza como uma das mais significativas formas de estabelecer parâmetros de sociabilidade assimétrica.

Além disso, 'gênero' dá ênfase ao caráter fundamentalmente social, cultural, das distinções baseadas no sexo, afastando o fantasma da naturalização; dá precisão à ideia de assimetria e de hierarquia nas relações entre homens e mulheres, incorporando a dimensão das relações de poder; dá relevo ao aspecto relacional entre as mulheres e os homens, ou seja, de que nenhuma compreensão de qualquer um dos dois poderia existir através de um estudo que os considerasse totalmente em separado, aspecto essencial para "descobrir a amplitude dos papéis sexuais e do simbolismo sexual nas várias sociedades e épocas, achar qual o seu sentido e como funcionavam para manter a ordem social e para mudá-la"( SCOTT, 1990, p. 88).

A articulação do gênero é também realizada com categorias como raça/ etnia e classe social, sendo a estruturação do poder econômico um importante elemento de organização simbólica das distinções de gênero. Isso significa dizer que a linguagem, como um ambiente privilegiado da teorização de gênero, possibilita estruturar as 
relações de poder dentro de uma determinada sociedade que vincula padrões de diferenciação e identidade a partir das diferenças percebidas entre os sexos. Assim, existirão diferenças não só entre mulheres e homens, mas entre mulheres e mulheres de diferentes classes, raça/ etnia, religião, educação, etc. Da mesma, entre homens e homens de distintos lugares simbólicos.

\section{GÊNERO E MOVIMENTO SOCIAL}

É preciso lembrar que nem todas as fissuras que corroem as formas de dominação masculina tomam a forma de dilacerações espetaculares, nem se exprimem sempre pela irrupção singular de um discurso de recusa ou de rejeição. Elas nascem com frequência no interior do próprio consentimento, quando a incorporação da linguagem da dominação se encontra reempregada para marcar uma resistência.

Desde o seu surgimento, as religiões são um fator importante para a constituição dos valores e grupos sociais. Os papeis de gênero, portanto, também são influenciados por elas. A partir dos anos 60, com o início da luta feminista, os valores tanto da mulher quanto do homem começaram a ser ressignificados no discurso social ocidental. É importante verificar se, atualmente, as religiões ainda postulam uma mulher apenas submissa, ou se as mesmas já estão se adequando às concepções contemporâneas do feminismo (HÖRLLE, 2010).

Existem inúmeras maneiras de expressão no tocante às questões de gênero e seu diálogo, interação e assimilação com os movimentos sociais a partir do movimento feminista, que começou a questionar de maneira mais incisiva a questão relacionada aos papeis das mulheres. Nesse sentido, pode-se entender que o feminismo teve uma função importante na vida de diferentes grupos de pessoas no que tange ao processo de dar visibilidade à história das mulheres e sua exclusão das narrativas acerca da construção das sociedades humanas. O feminismo enquanto fenômeno histórico adentrou e despertou as mulheres a perceberem suas concepções a respeito de como sua corporeidade é percebida na relação entre os sexos. 
Os movimentos feministas, de gays e lésbicas vêm estabelecendo suas pautas em lutas sociais que, muitas vezes, estruturam-se em teorizações de gênero. Especificamente os movimentos feministas compreendiam inicialmente a identidade da mulher de modo definido e genericamente compartilhado, passando ao longo do tempo a perceberem a fluidez das identidades. O sujeito mulher do feminismo foi desarticulado teoricamente e se passou a considerar que não existiria uma natureza essencial ou uma caraterística fundamentalmente feminina das mulheres que fosse biologicamente fixa ou filosoficamente metafísica. Não existe na natureza uma identidade essencial do sexo, a mulher não existe, ou como disse De Beauvoir: "Não se nasce Mulher, torna-se Mulher" (BEAUVOIR, 1980, p. 9).

A identidade de gênero feminina para uma mulher, embora a sociedade tenha se transformado e muitos dos conceitos moralistas, machistas e sexistas tenham perdido força, ainda está atrelada à ideia do bom comportamento, do recato, do cuidado, da sensibilidade. Tudo que foge a isso é visto como moralmente incorreto. $\mathrm{Na}$ ordem capitalista vigente, esses ideais morais quando alinhados ao regime econômico tendem a mais uma vez normalizar corpos e modos de vida, criticando determinados usos e operações no corpo e na imagem, e muito mais objetivamente quando se trata do corpo feminino já que esse é duplamente disciplinado por uma economia patriarcal e capitalista (AGUINSKY, 2013, p. 227).

A partir da noção de identidade buscada pela luta dos movimentos sociais, se dispenderam forças identitárias na conquista de espaços e visibilidade de grupos marginalizados, fragilizando o questionamento da própria ordem social vigente. Como resultado, observa Butler, as possibilidades políticas da crítica radical às estruturas de dominação social do patriarcado têm como consequência a constante vigilância epistêmica a respeito do risco de retorno a antigas posições de submissão por parte das mulheres.

[...] já não está claro que a teoria feminista tenha que tentar resolver as questões da identidade primária para dar continuidade à tarefa política. 
Em vez disso, devemos nos perguntar: que possibilidades políticas são consequências de uma crítica radical das categorias de identidade? Que formas novas de política surgem quando a noção de identidade como base comum já não restringe o discurso sobre políticas feministas? E até que ponto o esforço para localizar uma identidade comum como fundamento para uma política feminista impede uma investigação radical sobre as construções e as normas políticas da própria identidade? (BUTLER, 2010, p. 9-10).

Os movimentos sociais feministas, gays e lésbicas deram ênfase à luta identitária por motivos legítimos, pois não se sentiram contemplados nas grandes narrativas da modernidade como o marxismo e a psicanálise, optando pelo viés da afirmação de seus espaços nas sociedades contemporâneas. Permanecem, todavia, limitações quanto à vulnerabilidade das próprias identidades ao não se transformar a raiz cultural da moralidade e da desigualdade na qual se estrutura o patriarcado. Esse tensionamento entre luta identitária e transformação das culturas de exclusão acompanha o processo de constituição dos Estados Democráticos de Direito efetivados e construídos a partir da Segunda Guerra Mundial, perfazendo dinâmicas graduais de avanço nas políticas de reconhecimento das identidades abarcadas pelos valores constitucionais da democracia liberal.

A questão de gênero e a historiografia se encontram na envergadura educacional, uma vez que as diferenças percebidas entre os sexos se constituem privilegiadamente nos processos de reprodução dos valores sociais por meio do ensino cotidiano formal e informal. Os movimentos sociais se imbricam nas categorias de classe social, gênero e etnia/ raça para elaborar pautas de atuação, negociando identidades no limiar da ordem do público e do privado. Nesse sentido, a teorização de gênero ajuda a pesquisa em história a perceber como a linguagem estabelece as relações binárias subjetivas do cotidiano emoldurado pelas diferenças (ALMALEH,2018). 


\section{CONSIDERAÇÕES FINAIS}

Este artigo teve o objetivo principal de problematizar introdutoriamente as dificuldades para a pesquisa em história a respeito da dinâmica entre a luta por identidades e uma crítica radical de moralidades binárias. Não é um tema que possa ser tratado em poucas páginas, mas cabe alguns apontamentos a título de pesquisa exploratória acerca do tema. O gênero, como analisado, enfrenta a temática acerca da construção social da diferença sexual, seja ela entre mulheres e homens, seja entre mulheres e mulheres, homens e homens ou entre homens e mulheres e identidades dísforas. A teorização de gênero busca abordar as maneiras pelas quais as sociedades entendem o que é "ser homem" e "ser mulher" desde a análise histórica da linguagem como ambiente de significâncias. Portanto, gênero e história tangenciam-se na elaboração crítica do cotidiana dos processos de reificação das relações sociais binárias.

\section{REFERÊNCIAS}

AGUINSKY, Beatriz Gershenson; FERREIRA, Guilherme Gomes. Movimentos sociais de sexualidade e gênero: análise do acesso às políticas públicas. Revista Katál., Florianópolis, v. 16, n. 2, p. 223-232, jul./dez. 2013. p. 227. Disponível em: <http://www.scielo.br/pdf/rk/v16n2/08.pdf>. Acesso em: 19 nov. 2017.

ALMALEH, Priscilla. Ser mulher: cotidianos, representações e interseccionalidades da mulher popular (Porto Alegre: 1889-1900). Dissertação (Mestrado em História) - Programa de Pós-Graduação em História, Universidade do Vale do Rio dos Sinos, São Leopoldo, 2018. p. 28.

AVELAR, Alexandre de Sá. Escrita biográfica e escrita da história no pensamento de Wilhelm Dilthey. Dimensões, v. 38, jan.-jun. 2017, p. 120-142. Disponível em: $<w w w . p e r i o d i c o s . u f e s . b r / d i m e n s o e s / a r t i c l e / v i e w F i l e / 16809 / 11599>$. Acesso em: 08 abr. 2018.

BEAUVOIR, Simone de. O Segundo Sexo, v. 2, II. Rio de Janeiro: Nova Fronteira, 1980. 
BOURDIEU, Pierre. A dominação masculina. 12. ed. Rio de Janeiro: Bertrand Brasil, 2014.

BUTLER, Judith. Problemas de gênero: feminismo e subversão da identidade. Rio de Janeiro: Civilização Brasileira, 2010.

ESTEVES, Martha de Abreu. Meninas perdidas: os populares e o cotidiano do amor no Rio de Janeiro da belle époque. Rio de Janeiro: Paz e Terra, 1989.

GEBARA, Ivone. Rompendo o Silêncio: Uma fenomenologia feminista do mal. São Paulo: Vozes, 2000.

GONÇALVES, Andréa Lisly. História \&... gênero. Belo Horizonte: Autêntica, 2006.

HÖRLLE, Kyndze Rodrigues; TERRA, Ana Pereira; BRUNNET, Alice Einloft. Relações de gênero e religiões: os papéis designados à mulher. In: XI SALÃO DE INICIAÇÃO CIENTÍFICA - $\quad$ PUCRS $2010 . \quad$ Disponível em: $<$ http://www.pucrs.br/edipucrs/XISalaolC/Ciencias_Humanas/Psicologia/84232KYNDZERODRIGUESHORLLE.pdf>. Acesso em: 19 nov. 2017.

LUKÁCS, Georg. História e consciência de classe: estudos de dialéctica marxista. Porto: Publicações Escorpião, 1974.

PEDRO, Joana Maria. Relações de gênero como categoria transversal na historiografia contemporânea. Topoi, Rio de Janeiro, v. 12, n. 22, p. 270-283, jan./jun. 2011. Disponível em: <http://www.revistatopoi.org>. Acesso em: 24 mar. 2019.

SCOTT, Joan. Gênero, uma categoria útil de análise histórica. Educação e Realidade, Porto Alegre, 16(2) 5-22, jul/dez. 1990. Disponível em: <https://seer.ufrgs.br/educacaoerealidade/article/view/71721/40667>. Acesso em: 23 mar. 2019.

SOIHET, Rachel; PEDRO, Joana Maria. A emergência da pesquisa da História das Mulheres e das Relações de Gênero. Revista Brasileira de História, São Paulo, v. 
27, n. 54, 2007. p. 288. Disponível em: <http://www.scielo.br/scielo.php?pid=S010201882007000200015\&script=sci_abstract\&tIng=pt>. Acesso em: 23 mar. 2019.

SPIZZIRRI, Giancarlo et al. O termo gênero e suas contextualizações. Diagn Tratamento, 19(1), p. 42-44, 2014. Disponível em: <http://files.bvs.br/upload/S/14139979/2014/v19n1/a3969.pdf>. Acesso em: 23 mar. 2019.

ZIZEK, Slavoj. Eles não sabem o que fazem: o sublime objeto da ideologia. Rio de Janeiro: Jorge Zahar, 1992.

Enviado: Outubro, 2019.

Aprovado: Janeiro, 2020. 